\title{
The nutritional quality improvement of dried gluten free pasta supplemented with Cladophora spp.
}

\author{
Patchareeporn Choobthaisong ${ }^{1}$, Orawan Oupathumpanont ${ }^{2 *}$ \\ ${ }^{1}$ Department of Home Economics Technology, Faculty of Home Economics Technology, Rajamangala University of Technology Thanyaburi, \\ 39 Moo 1, Klong 6, Khlong Luang Pathum Thani 12110 Thailand, '2Department of Food and Nutrition, Faculty of Home Economics Technology, \\ Rajamangala University of Technology Thanyaburi, 39 Moo 1, Klong 6, Khlong Luang Pathum Thani 12110 Thailand
}

\section{A B S T R A C T}

\begin{abstract}
This research aimed to study: 1) the suitable formula gluten free pasta supplemented with Cladophora spp., 2) the chemical and physical properties of pasta supplemented with Cladophora spp., and 3) the consumer acceptance. A mixture design experiment was conducted, and three factors were analyzed, 50-70\% brown rice flour, 15-25\%modified starch, and 10-20\% Cladophora spp., the most suitable formula indicated $68 \%$ brown rice, $22 \%$ modified starch, $10 \%$ Cladophora spp. The nutritional profile of this gluten-free pasta per 100 grams was 379.00 kilocalories of total energy, 7.09 grams of protein, 1.91 grams of dietary fiber, 0.11 milligrams of vitamin $B, 0.11$ milligrams of vitamin B2, 31.30 milligrams of calcium, and 3.84 milligrams of iron and antioxidant activity 48.50 mg eq Trolox. Most consumers' overall liking score was at a moderate level. The gluten-free pasta supplemented with Cladophora spp. will make better nutrition value.
\end{abstract}

Keywords: Pasta; Brown rice flour; Modified starch; Cladophora spp.; mixture design

\section{INTRODUCTION}

Nowadays healthy foods gain popularity increasingly. Consumers give importance to consideration of benefits and nutritional value of foods before they consume to gain maximum benefits. Food consumption is directly related to a person's health. Due to lifestyle changes, foods eaten are causes of life-threatening diseases such as diabetes, cancer, hypertension, heart disease, etc. (Kaur, S. and Das, M., 2011). Foods produced from natural raw materials have high nutrient value. Green algae looks like a long fresh green thread and has a lot of branches. It can be generally found in small streams or rivers where there is continuous flow of clear and clean water, benthic zone is full of small and large stones and sunlight can reach. It is most likely found in deep water, with a depth not exceeding 1 meter. It floats at a river bed level to the water surface. It is found during winter to summer. Cladophora spp. is eaten fresh as well as dried and sold in markets. Cladophora spp. is processed to be several products such as Cladophora spp. chili paste, seasoned crispy Cladophora spp. chip, Cladophora spp. cookie, Cladophora spp. crip rice, 100 grams of dried Cladophora spp. contain important nutrients, $30.80 \%$ carbohydrate, $21.50 \%$ fiber, $19.90 \%$ protein, $4.63 \%$ fat and various minerals such as calcium, potassium, selenium (Peerapornpisal, Y., 2007) Furthermore, Cladophora spp. has property of inhibiting dystonia, anti-inflammatory property, analgesic property, and reducing blood pressure (Peerapornpisal, Y. et al., 2006)

Pasta is a noodle product popular among consumers across the world. It majorly contains carbohydrate called starch. People in many countries like to eat pasta as a staple food and this type of food also gains popularity among consumers. It possesses unique nutritional as a low GI product which is slowly digested and absorbed in the small intestine (Brennan, C. S. and C. M. Tudorica., 2008). However, it is still typically made from durum wheat flour containing gluten. Gluten gives negative impacts of human health, particularly in the coeliac disease patients who are intolerance to this protein fraction (Rosell, C.M. et al., 2014). Currently, the only effective therapy is based on a life-long adherence to a gluten free diet (Bouasla, A. et al., 2017).

Today, studies are conducted on developing gluten free pasta products from different flour types such as tapioca

\footnotetext{
*Correspontding author:

Orawan Oupathumpanont, Department of Food and Nutrition, Faculty of Home Economics Technology, Rajamangala University of Technology Thanyaburi, 39 Moo 1, Klong 6, Khlong Luang Pathum Thani 12110 Thailand. E-mail: orawan_o@rmutt.ac.th
}

Received: 14 April 2021; $\quad$ Accepted: 25 June 2021 
flour (cassava flour), quinoa flour, millet rice flour, white bean flour, buckwheat flour, pumpkin flour, broad bean flour, etc. especially rice-based processed flour from both Oryza sativa rice and sticky rice since rice is a source of gluten free whole grain. Brown rice flour is chosen to be a main raw material in producing pasta is to reduce the import of wheat and a trade deficit. Brown rice is unpolished rice. It contains large quantities of rice germ and aleuronic layer and contains more protein, fat, fiber, vitamin, and minerals than white rice. Moreover, brown rice contains anthocyanin compound, a pigment most commonly found in the aleuronic layer and antioxidant that inhibits the oxidation of cholesterol and reduces the risk of heart disease and cancer. Gluten free flour needs to add a stabilizer like a gum to replace gluten in wheat flour so as to improve the structure of pasta from rice flour. In addition, there are research papers related to producing pasta from rice-modified starch or pregel as an ingredient, having an effect on improving pasta sensory evaluation in terms of texture (Mongkolchart, P. et al., 2016.).

Therefore, the objective of this research was to improvement the nutrition value of gluten free pasta by study a suitable formula supplement with Cladophora spp. In addition, the physical properties, nutritional profile, microbial quality and sensory acceptance of gluten free pasta supplemented with Cladophora spp. were determined.

\section{MATERIALS AND METHODS}

\section{Cladophora spp. powder preparation}

Cladophora spp. were purchased from local market in Tha Wiang Pha District, Nan Province and cleaned fresh Cladophora spp. and drained, then dried in a hot air oven at $60{ }^{\circ} \mathrm{C}$ until its moisture content did not exceed $10 \%$. Dried Cladophora spp. were blended using a blender. The powder obtained was then sieved through a 100 mesh and contain the Cladophora spp. powder sealed in polypropylene plastic bag. The packed flour were then stored in chiller at $5 \pm 2{ }^{\circ} \mathrm{C}$

\section{Study the suitable formula}

There were 3 factors in this study included the amounts of brown rice powder $50-70 \%$, modified starch $15-25 \%$, and Cladophora spp. powder 10-20\%. A mixture design method was used in the experiment. The basic formula is showed in Table 1, which was used to produce pasta supplemented with Cladophora spp. according to the process shown in Fig. 1.

The obtained was analyzed for quality as follows:

\section{Physical quality}

Cutting and shearing force analysis. The samples were prepared by put 100 gram of the pasta supplemented with
Table 1: The basic formular for producing pasta

\begin{tabular}{lc}
\hline Ingredients & Quantity (\%) \\
\hline brown rice powder & $50-70$ \\
modified starch & $15-25$ \\
Cladophora spp. powder & $10-20$ \\
guar gum & 0.05 \\
salt & 0.05 \\
egg & 2.00 \\
olive oil & 2.00 \\
water & 20.00 \\
\hline
\end{tabular}

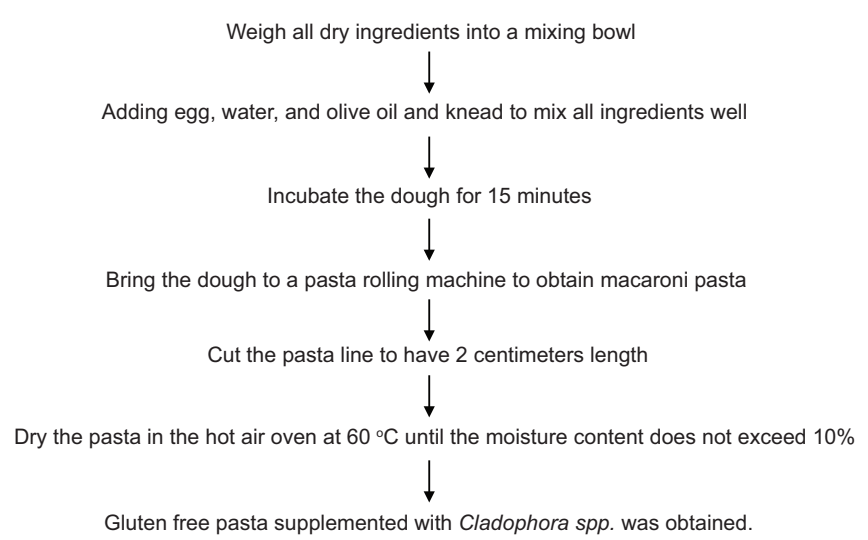

Fig 1. Production process of Gluten free pasta supplemented with Cladophora spp.

dried Cladophora spp in 1 liter boiling water for 10 minutes after that drained. The cutting (Blade set with Knife) and shearing (Warner Bratzler Blade) force were measured using a Texture Analyzer (TA-XT plus texture analyzer, Stable Micro System). The velocity of the blade movement is required by 10 millimeters per second (Oupathumpanont, O., 2019). The suitable formula was devised based on cutting and shearing force value and used K-mean cluster analysis method for grouping compared with the commercial gluten free pasta product (control)

\section{Consumer preference test}

Consumer preference from 50 consumers were studied. Central Location Test (CLT) was performed using the 9-point Hedonic in appearance, color, overall flavor, elasticity, cohesiveness, softness, and overall liking of pasta without and with minced chicken in tomato sauce.

\section{Statistical analysis}

All data obtained from the physical analysis and consumer preference test were using Analysis of variance (ANOVA). In case of significant, Duncan's new multiple range test (DMRT) was applied to test the difference of means.

\section{Evaluation of the quality of gluten free pasta supplemented with Cladophora spp. Physical quality}

The color of the dried pasta samples were measured with a Hunter Lab, Miniscan XE Plus (Minolta, Tokyo, 
Japan). The $L^{*}, a^{*}$ and $b^{*}$ readings were obtained directly from the instrument and provided measures of lightness, redness and yellowness, respectively. All measurements were performed in triplicate (Jha, S. N., 2010). The water activity $\left(\mathrm{a}_{\mathrm{w}}\right)$ of the dried pasta samples were measured with Aqua Lab, Model CX3TE (AOAC, 2020). The cutting and shearing force of cooked pasta samples were measured with a TA-XT plus texture analyzer (Stable Micro System) (Oupathumpanont, O., 2019)

\section{Chemical quality}

Analysis of moisture content, protein, fat, fiber and ash content were conducted based on AOAC (2020). Antioxidant determination include diphenyl-picryhydrazyl (DPPH) by Nguyen et al. (2012)

\section{Microorganisms quality}

Aerobic Plate Count, Total Yeast and Mold, Coliform Bacteria (AOAC, 2020).

\section{Sensory quality}

This assessment was conducted to determine the preference of 100 consumer individuals (aged 20 years and over divided) who consumed pasta in tomato sauce with minced chicken. Central Location Test (CLT) was performed using 9-point hedonic scale.

\section{RESULTS AND DISCUSSION}

\section{The study on a suitable formula}

After the mixture design method was applied for experiment. There are 16 formulas that used to make pasta was shown in Fig. 2

Subsequently, 16 formulae were used to produce the gluten free pasta supplemented with Cladophora spp. The quality of dough and pasta were analyzed and Group separation by $\mathrm{K}$-mean cluster analysis. The results shown in Fig. 3.

From the Fig. 3, Among the 3 different groups, the focus was on the group 3 (formulas; 2: 70\% brown rice powder, 15\% modified starch and 15\% Cladophora spp. powder, 3: $70 \%$ brown rice powder, $20 \%$ modified starch and 10\% Cladophora spp. powder, 8: 68\% brown rice powder, $22 \%$ modified starch and $10 \%$ Cladophora spp. powder and control). This group had the highest level of cutting and shearing force values. In this group had a large quantity of modified starch that had effect on water absorption property to transform into gel and hold other ingredients, making the mixture combined homogenously to enable the product to be cohesiveness and elasticity which were good sensory evaluation of pasta. (Sriroth, K. et al., 2003). The high cutting and shearing force value will indicate high cohesiveness and elasticity of texture (Oupathumpanont,
O., 2019). Then, gluten free pasta supplemented with Cladophora spp. from group 3 was brought to study consumer preference test without and with minced chicken in tomato sauce. The 9-point hedonic scale was used by considering appearance, color, overall flavor, elasticity, cohesiveness, softness, and overall liking of 50 consumers. The results was shown in Table 2 and 3.

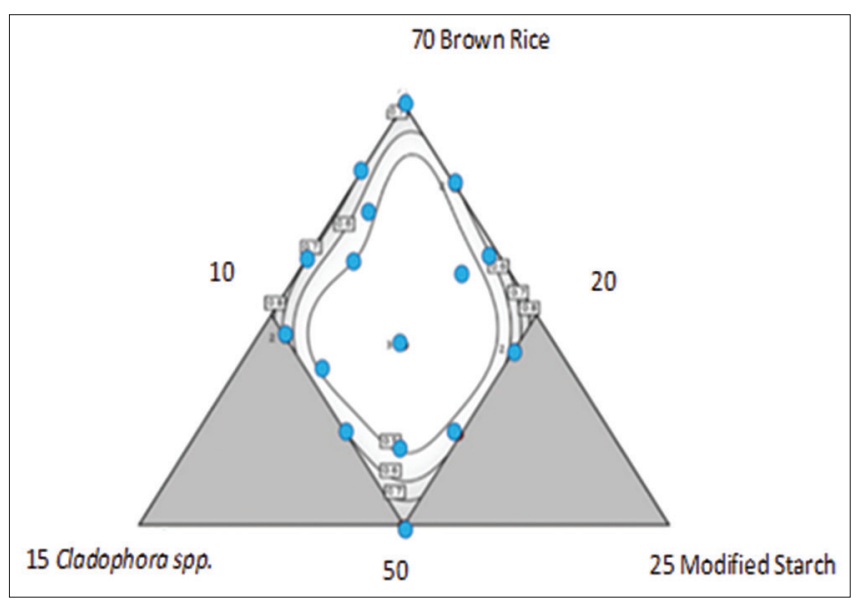

Fig 2. Various formulas for producing gluten free pasta supplemented with Cladophora spp.

Table 2: Mean values of the preference score in characteristics of gluten free pasta supplemented with Cladophora spp.

\begin{tabular}{lccc}
\hline Characteristics & \multicolumn{3}{c}{ The mean of preference score } \\
\cline { 2 - 4 } & Formula 2 & Formula 3 & Formula 8 \\
\hline Appearance & $6.52^{\mathrm{b}} \pm 0.91$ & $6.56^{\mathrm{b}} \pm 1.23$ & $8.02^{\mathrm{a}} \pm 0.71$ \\
Color & $7.96^{\mathrm{b}} \pm 0.76$ & $7.84 \mathrm{a}^{\mathrm{b}} \pm 0.68$ & $8.16^{\mathrm{a}} \pm 0.71$ \\
Overall Flavor & $7.86^{\mathrm{b}} \pm 0.76$ & $8.02 \mathrm{a}^{\mathrm{b}} \pm 0.69$ & $8.22^{\mathrm{a}} \pm 0.74$ \\
Elasticity & $6.32^{\mathrm{b}} \pm 1.04$ & $6.28^{\mathrm{b}} \pm 1.31$ & $7.54^{\mathrm{a}} \pm 1.05$ \\
Cohesivenessns & $6.84 \pm 1.15$ & $7.42 \pm 1.16$ & $7.60 \pm 1.14$ \\
Softness & $6.82^{\mathrm{b}} \pm 1.44$ & $7.56^{\mathrm{a}} \pm 1.15$ & $7.64^{\mathrm{a}} \pm 1.03$ \\
Overall liking & $6.52^{\mathrm{b}} \pm 0.96$ & $6.46^{\mathrm{b}} \pm 1.09$ & $7.72^{\mathrm{a}} \pm 1.07$ \\
\hline
\end{tabular}

Remark: ns:non significant $(p>0.05)$

$\mathrm{a,b}$ are mean values in the same row followed by different letters are significant $(p<0.05)$

\pm Standard Deviation

Table 3: Mean values of the preference score in characteristics of pasta supplemented with Cladophora spp. in minced chicken in tomato sauce

\begin{tabular}{lccc}
\hline Characteristics & \multicolumn{3}{c}{ The mean of preference score } \\
\cline { 2 - 4 } & Formula 2 & Formula 3 & Formula 8 \\
\hline Appearance & $6.52^{\mathrm{b}} \pm 1.05$ & $6.46^{\mathrm{b}} \pm 1.11$ & $7.42^{\mathrm{a}} \pm 0.95$ \\
Color & $7.96^{\mathrm{b}} \pm 0.76$ & $7.84^{\mathrm{ab}} \pm 0.68$ & $8.16^{\mathrm{a}} \pm 0.71$ \\
Overall Flavor & $7.86^{\mathrm{b}} \pm 0.76$ & $8.02^{\mathrm{ab}} \pm 0.69$ & $8.22^{\mathrm{a}} \pm 0.74$ \\
Elasticity & $6.44^{\mathrm{b}} \pm 1.13$ & $6.60^{\mathrm{b}} \pm 1.20$ & $7.50^{\mathrm{a}} \pm 0.89$ \\
Cohesivenessns & $6.82 \pm 1.44$ & $7.52 \pm 1.15$ & $7.64 \pm 1.03$ \\
Softness & $6.04^{\mathrm{b}} \pm 0.90$ & $6.06^{\mathrm{b}} \pm 1.02$ & $6.92^{\mathrm{a}} \pm 1.04$ \\
Overall liking & $6.92^{\mathrm{b}} \pm 0.90$ & $7.12^{\mathrm{b}} \pm 0.96$ & $7.64^{\mathrm{a}} \pm 0.88$ \\
\hline
\end{tabular}

Remark: ${ }^{n s}$ :non significant $(p>0.05)$

$a, b$ are mean values in the same row followed by different letters are significant $(p<0.05)$

\pm Standard Deviation. 


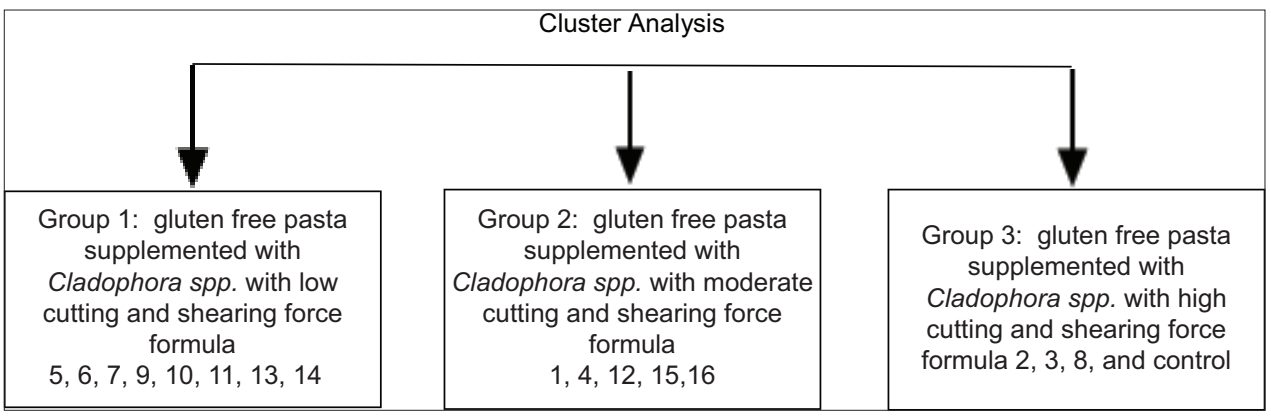

Fig 3. Cluster analysis of 16 formulas by evaluation of cutting and shearing force of the gluten free pasta supplemented with Cladophora spp. groups

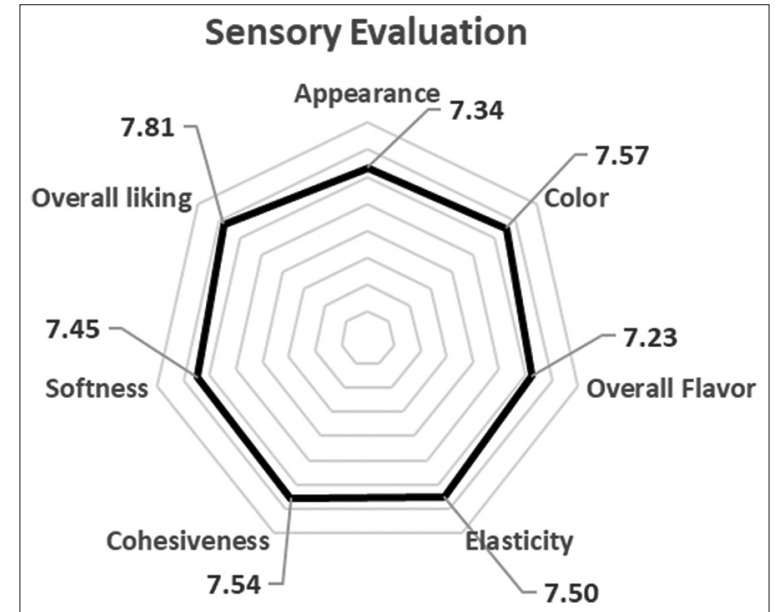

Fig 4. Liking score in sensory evaluation of the gluten free pasta product supplemented with Cladophora spp.

From Table 2 and 3 , the results showed that the liking scores among all pasta formulation were significant $(\mathrm{p}<0.05)$. The formula 8 exhibited the highest preference score for appearance, color, overall flavor, elasticity, softness and overall liking. Formula 8 consists of brown rice flour $68 \%$, modified starch $22 \%$, and Cladophora spp. $10 \%$. Consequently, the best suited for producing gluten free pasta supplemented with Cladophora spp. was formula 8 that had available in less quantities of Cladophora spp. and higher brown rice flour than formula 2 and 3. In the present study, Cladophora spp. and brown rice flour were a source of fiber that had effect on texture properties and Sangnark, A. and A. Noomhorn. (2004) reported that high fiber ingredients increases the softness and elasticity were decreases. The main characteristics of pasta that affect the taste are softness and elasticity.

\section{Evaluation of the quality of gluten free pasta supplemented with Cladophora spp.}

Gluten free pasta supplemented with Cladophora spp. formula 8 was produced and study on physical, chemical, microorganisms quality and consumer acceptance was shown in Table 4 and Fig. 4.

The physical, chemical, microorganism quality of 100 grams gluten free pasta supplemented with Cladophora spp.
Table 4: The study on physical, chemical, microorganism quality of 100 grams gluten free pasta supplemented with Cladophora spp.

\begin{tabular}{lcl}
\hline Quality & Quantity & Unit \\
\hline Cutting force & $4,480.07$ & $\mathrm{gf}$ \\
Shearing force & $4,781.67$ & $\mathrm{gf}$ \\
Water activity $\left(\mathrm{a}_{\mathrm{w}}\right)$ & 0.44 & \\
$\mathrm{~L}^{*}$ & 22.20 & \\
$\mathrm{a}^{*}$ & -1.80 & \\
$\mathrm{~b}^{*}$ & 15.50 & \\
Antioxidant activity & 48.50 & $\mathrm{mg} \mathrm{eq}$ Trolox $/ 100 \mathrm{~g}$ \\
Moisture & 8.83 & $\mathrm{~g}$ \\
Total energy & 379.00 & $\mathrm{Kcal}$ \\
Energy from fat & 36.50 & $\mathrm{Kcal}$ \\
Total fat & 4.05 & $\mathrm{~g}$ \\
Saturated fat & 1.25 & $\mathrm{~g}$ \\
Cholesterol & 37.00 & $\mathrm{mg}$ \\
Protein & 7.09 & $\mathrm{~g}$ \\
Carbohydrate & 78.49 & $\mathrm{~g}$ \\
Dietary fiber & 1.91 & $\mathrm{~g}$ \\
Sugar & $\mathrm{ND}$ & $\mathrm{g}$ \\
Vitamin a & $\mathrm{ND}$ & $\mathrm{mg}$ \\
Vitamin B1 & 0.11 & $\mathrm{mg}$ \\
Vitamin B2 & 0.11 & $\mathrm{mg}$ \\
Calcium & 31.30 & $\mathrm{mg}$ \\
Iron & 3.84 & $\mathrm{mg}$ \\
Aerobic Plate Count & 50 & $\mathrm{CFU} / \mathrm{g}$ \\
Total Yeast and Mold & $<10$ & $\mathrm{CFU} / \mathrm{g}$ \\
Coliform Bacteria & $<10$ & $\mathrm{CFU} / \mathrm{g}$ \\
\hline
\end{tabular}

present in Table 4. It was found that antioxidant activity, dietary fiber, calcium and iron were high which came from Cladophora spp.

Based on the sensory evaluation result (Fig.4), the highest mean value of the preferemce score was observed for overall liking; further the result for appearance, color, overall flavor, elasticity, cohesiveness and softness attributes implied that the pasta supplemented with Cladophora spp. was liked moderately. Moreover, $85.43 \%$ of the consumers showed their onterest in buying the gluten free pasta supplemented with Cladophora spp.because it was suitable for people with gluten intolerance. In addition, it was a healthy and nutritious food product. 


\section{CONCLUSION}

The suitable formula for producing gluten free pasta supplemented with Cladophora spp. was included brown rice power $68 \%$, modified starch $22 \%$, and Cladophora spp. power 10\%.The nutritional quality, it contained antioxidant activity $48.50 \mathrm{mg}$ eq Trolox/100g, 1.91 grams of fiber, 31.30 milligrams of calcium, 3.84 milligrams of iron. Overall preference for consumer is at moderate level and $85.43 \%$ of consumer are interested in purchasing pasta supplemented with Cladophora spp. because it was a healthy food.

\section{ACKNOWLEDGEMENTS}

The authors would like to thank the Faculty of Home Economics Technology, Rajamangala University of Technology Thanyaburi, Thailand for generous laboratory workplaces.

\section{CONFLICTS OF INTEREST}

The authors declare no conflict of interest.

\section{REFERENCES}

AOAC. 2020. Official Methods of Analysis, Association of official Analytical Chemists, Washington, DC.

Bouasla, A., A. Wojtowicz and M. N. Zidoune. 2017. Gluten-free precooked rice pasta enriched with legumes flours: Physical porperties, texture, sensory attributed and microstructure. LWT
Food Sci. Technol. 75: 569-577.

Brennan, C. S. and C. M. Tudorica. 2008. Evaluation of potential mechanisms by which dietary additions reduce the predicted glycaemic index of fresh pasta. Int. J. Food Sci. Technol. 43: 2151-2162.

Jha, S. N. 2010. Colour measurements and medeling. In: Jha, S. (Ed.), Nondestructive Evaluation of Food Quality, Springer, Berlin p. 29.

Kaur, S. and M. Das. 2011. Functional foods: An overview. Food Sci. Biotechnol. 20(4): 881-875.

Mongkolchart, P., E. Araki, K. Ashida, N. Aoki, M. Takahashi, S. Hamada. 2016. Quality Development of Rice Flour to Replace Wheat in Producing Noodle and Bread Types of Food. (Research Report), Agriculture Science and Biology Program, Office for CommunityTechnology, Department of Science Service, Bangkok.

Oupathumpanont, O. 2019. Development of Gluten Free Pasta from Banana Flour, (Research Report), Faculty of Home Economics Technology, Rajamangala University of Technology Thanyaburi, Pathum Thani.

Peerapornpisal, Y. 2007. Cladophora spp.: General Knowledge and Food Processing, Chotana Print Company Limited, Chiang Mai.

Peerapornpisal, Y., S. Makornkaewkeyoon, I. Pongsirikul, D. Amornlertpisal, J. Pekkoh and S. Tongsiri. 2006. Potential of Freshwater Macroalgae as Food and Medicine. (Research Report), The Thailand Research Fund (TRF), Chiang Mai.

Rosell, C. M., F. Barro, C. Sousa and M. C. Mena. 2014. Cereals for developing gluten-free products and analytical tools for gluten detection. J. Cereal Sci. 59: 354-364.

Sangnark, A. and A. Noomhorn. 2004. Chemical, physical and baking properties of dietary fibre prepared from rice straw. Food Res. Int. 37: 66-74.

Sriroth, K. and K. Piyajomkwan. 2003. Starch Technology. $3^{\text {rd }}$ ed. Kasetsart University Printing Center, Bangkok. 